\title{
Coffee consumption is inversely associated with depressive status in Japanese patients with type 2 diabetes
}

\author{
Katsuhisa Omagari, ${ }^{1, *}$ Mika Sakaki, ${ }^{1}$ Yuki Tsujimoto, ${ }^{2}$ Yukiko Shiogama, ${ }^{2}$ Akiko Iwanaga, ${ }^{2}$ Makiko Ishimoto, ${ }^{2}$ \\ Asami Yamaguchi, ${ }^{2}$ Miki Masuzumi, ${ }^{1}$ Miku Kawase, ${ }^{1}$ Mayuko Ichimura, ${ }^{3}$ Takatoshi Yoshitake ${ }^{4}$ and Yoshiyuki Miyahara $^{4}$
}

\author{
'Department of Nutrition, Faculty of Nursing and Nutrition and ${ }^{3}$ Division of Nutritional Sciences, Graduate School of Human Health Science, \\ University of Nagasaki, 1-1-1 Manabino, Nagayo-cho, Nagasaki 851-2195, Japan \\ ${ }^{2}$ Dietary Cure Unit and ${ }^{4}$ Department of Internal Medicine, Nagasaki Memorial Hospital, 1-11-54 Fukahori, Nagasaki 851-0301, Japan
}

(Received 24 February, 2014; Accepted 6 April, 2014; Published online 31 July, 2014)

\begin{abstract}
Depression has been reported to be more prevalent among diabetic patients than non-diabetic individuals. Although depression and diabetes are causally and bi-directionally related, the influence of food intake frequency on depressive symptoms in diabetic patients has not been fully evaluated. This cross-sectional study analyzed data obtained from 89 patients with type 2 diabetes who completed self-administered questionnaires regarding food intake frequency, diabetic variables, physical activity and depressive states. The prevalence of a "definite" depressive state was $16.9 \%$. The duration of diabetes, hemoglobin A1c levels, diabetic microvascular complications and physical activity levels were similar between depressed and non-depressed patients. Daily intakes of total lipids, $n-6$ polyunsaturated fatty acids and lipid energy ratios were significantly lower, and the carbohydrate energy ratio was significantly higher in depressed than in nondepressed patients. Coffee consumption was inversely associated with depressive symptoms, but no significant association was found between tea or green tea consumption and depressive symptoms. The logistic regression analysis showed that coffee consumption was an independent predictor of non-depressed status in diabetic patients. This might be due to biologically active compounds containing in coffee other than caffeine.
\end{abstract}

Key Words: depression, diabetes mellitus, food intake, coffee consumption

$\mathrm{D}$ epression is the most prevalent psychiatric condition and the estimated lifetime prevalence of major depression in Japan is $3-7 \%$. $^{(1)}$ Depression is associated with poor health behaviors such as cigarette smoking, physical inactivity and caloric intake that might increase risk for type 2 diabetes. ${ }^{(2)}$ Indeed, depression is apparently more common among diabetic patients than nondiabetic individuals. ${ }^{(2-6)}$ Anderson et al. ${ }^{(4)}$ reported that the odds of depression in a diabetic group were twice that of a non-diabetic comparison group. Mezuk et $a l^{(2)}$ also reported that the relative risk for incident depression associated with baseline diabetes was 1.15. On the other hand, Kawakami et $a l .{ }^{(3)}$ found that patients with moderate or severe levels of depressive symptoms at baseline had a 2.3-fold higher risk of developing type 2 diabetes. Mezuk et al. ${ }^{(2)}$ also reported that the relative risk for incident diabetes associated with baseline depression was 1.60. Thus, the relationship between depression and diabetes is bi-directional and causal. Diabetes might worsen the course of depression and depression is a risk factor for the development of diabetes. ${ }^{(7)}$

Diabetes is a serious metabolic disorder that imposes lifechanging consequences upon affected individuals. It might increase risk for depression because of the sense of threat and loss associated with being diagnosed with diabetes and the substantial lifestyle changes necessary to avoid developing debilitating complications. (2) Diabetic patients who are depressed have poorer glycemic control, are less physically active and more likely to be obese. ${ }^{(5)}$ Moreover, depression further deteriorates the quality of life of patients with type 2 diabetes. ${ }^{(8)}$ Conversely, depression might precede the onset of type 2 diabetes and play an important role in its development. ${ }^{(3)}$ Depression is associated with hyperglycemia and increased risk for diabetic complications, ${ }^{(4)}$ which might be due, at least in part, to increased activity of the sympathoadrenal system as reflected by noradrenaline, dopamine and adrenaline in cerebrospinal fluid, plasma or urine, and a dysregulated hypothalamopituitary adrenal axis.(3) Depression is also related to central obesity and potentially to impaired glucose tolerance. ${ }^{(2)}$ Treating depression improves glycemic control. ${ }^{(4)}$

Recent studies have shown that low dietary intake or low serum/ plasma levels of nutrients such as $n-3$ polyunsaturated fatty acids (PUFAs), ${ }^{(9,10)}$ docosahexaenoic acid (DHA), ${ }^{(11)}$ eicosapentaenoic acid (EPA), ${ }^{(12)} \alpha$-linolenic acid, ${ }^{(10)}$ folate, ${ }^{(1,13,14)}$ and higher ratios of $n-6$ to $n-3$ PUFAs ${ }^{(9)}$ are linked to depression. Fish consumption, ${ }^{(15)}$ Mediterranean, ${ }^{(16)}$ Australian, ${ }^{(17)}$ healthy Japanese, ${ }^{(18)}$ whole food ${ }^{(19)}$ and traditional(20) diet patterns have also been reported to be associated with decreased prevalence of depressive symptoms. However, these findings in both men and women remain controversial. ${ }^{(21-24)}$

The present study investigated the prevalence of depression in patients with type 2 diabetes using the Japanese version of the hospital anxiety and depression scale (HADS) ${ }^{(25,26)}$ at a single institution, and assessed whether sociodemographic variables, health-related lifestyle variables including food intake frequency, and diabetic variables were associated with a depressive state.

\section{Materials and Methods}

Study participants. Between April and September 2013, 104 patients with type 2 diabetes who attended Nagasaki Memorial Hospital, Nagasaki-city, Japan, were invited to enroll, and 90 $(86.5 \%)$ patients agreed to participate. The diagnosis of type 2 diabetes had been made in accordance with the criteria established by the Committee of the Japan Diabetes Society.(27) All patients provided written informed consent to participate in the present study.

Study design. This cross-sectional study required the patients to complete self-administered questionnaires that were checked by

*To whom correspondence should be addressed.

E-mail: omagari@sun.ac.jp 
Table 1. Nutrients, food groups and dish categories estimated from FFQg questionnaire

\begin{tabular}{ll}
\hline Classification & \multicolumn{1}{c}{ Item estimated } \\
\hline Nutrients* & total energy; water; protein; total lipids; carbohydrates; ash; sodium; potassium; calcium; magnesium; phosphate; iron; zinc; \\
& copper; manganese; retinol; $\alpha-$, and $\beta$-carotene; cryptoxanthin; equivalent amount of $\beta$-carotene; equivalent amount of \\
& retinol; vitamin $D ; \alpha-, \beta-, \gamma-$ and $\delta$-tocopherol; equivalent amount of tocopherol; vitamin K; vitamins B1, B2, B6, and B12; \\
& niacin; folic acid; pantothenic acid; vitamin C; saturated fatty acids; mono-unsaturated fatty acids; poly-unsaturated fatty \\
& acids; cholesterol; water-soluble fibers; water-insoluble fibers; total fibers; salt; total fatty acids; $n$-3, and $n-6$ poly-unsaturated \\
& fatty acids \\
& cereals (rice, noodle, etc); potatoes and starches; green-yellow vegetables; light-colored and other vegetables; mushrooms; \\
& seaweed; beans; fish/shellfish; meats; eggs; milk/dairy products; fruits; snacks; beverages; sugar/sweets; nuts; oils/fats; \\
& seasonings/spices \\
Food groups* & grain dishes (rice, bread, noodles, and pasta); vegetable dishes; fish and meat dishes (meat, fish, egg, and soy-bean dishes); \\
& milk (milk and milk products); fruits; snacks, confection, and beverages
\end{tabular}

*According to the 2010 edition of Standard Tables of Food Composition in Japan. ${ }^{(29)}{ }^{*}$ *According to the Japanese Food Guide Spinning Top. ${ }^{(30)}$ FFQg, food frequency questionnaire based on food groups.

a hospital-registered dietitian for completeness and, if necessary, clarified by questioning the respondents. The questionnaires included sociodemographic and health-related lifestyle variables such as age, gender, height, body weight, physical activity status, sleeping hours, changes in body weight during the past 6 months, current occupation, number of family members that they live with, daily consumption of coffee, green tea, black tea and alcohol, smoking habit, and regular consumption of supplements for nutritional or health-related purposes. With respect to daily coffee consumption, caffeinated or decaffeinated coffee was not distinguished. Food intake and the physical activity levels were assessed in detail using the established semiquantitative questionnaire available for clinical investigation (a food frequency questionnaire based on food groups, the FFQg ver. 3.5; Kenpaku-sha, Tokyo, Japan). ${ }^{(28)}$ Body mass index (BMI) was calculated as body weight (kg) divided by height squared $\left(\mathrm{m}^{2}\right)$. Alcohol consumption was divided into 3 groups as follows: never drinker, occasional drinker (1-4 times per week), and habitual drinker (at least $23 \mathrm{~g} /$ day of alcohol consumed 5-7 times per week). This questionnaire survey was conducted between 9:00-11:00 am in Nagasaki Memorial Hospital.

Diabetic and other medical variables including duration of diabetes, treatment regimen, presence of diabetic microvascular complications such as diabetic neuropathy, retinopathy, and nephropathy, other conditions such as insomnia, number and duration of nutritional counseling sessions were obtained from the patient's medical records. Hemoglobin A1c (HbAlc) determined as described by the National Glycohemoglobin Standardization Program (NGSP) method within 60 days from the day of examination was also evaluated as a variable representing a glycemic control status.

Food intake frequency. Data regarding portion size and the frequency of consumption of 29 food groups, including staples (rice, bread and noodles), within one week were calculated using the established semiquantitative questionnaire FFQg ver. 3.5 (Kenpaku-sha). Using these data, the amount of each nutrient and food group determined according to the 2010 edition of the Standard Tables of Food Composition in Japan ${ }^{(29)}$ and the dish category determined according to the Japanese Food Guide Spinning Top ${ }^{(30)}$ were estimated using a computer software program based on the standard tables of food composition in Japan $2010^{(29)}$ (Table 1). The quantity of each dish category in the Japanese Food Guide Spinning Top was expressed as "tsu" or serving (SV), which is a simple number that approximates the amount of each dish or food served to one person in Japan. ${ }^{(30)}$

Physical activity levels. Physical activity levels (PAL) calculated as total energy expenditure (TEE) divided by basal metabolic rate (BMR) were estimated using a computer software program (FFQg ver. 3.5; Kenpaku-sha). ${ }^{(31)}$ For individuals between 30 to 69 years of age, a PAL of $<1.6$ was designated as level I, a PAL of 1.6-1.9 was designated as level II and a PAL of $>1.9$ was designated as level III. For individuals who were 70 years of age or more, a PAL of $<1.55$ was designated as level I, a PAL of 1.55-1.85 was designated as level II and a PAL of $>1.85$ was designated as level III. . $^{(32)}$

Psychological assessment. Symptoms of depression were assessed using the Japanese version of the hospital anxiety and depression scale (HADS), which has proven reliable and valid as a screening method for assessing emotional disorders among Japanese patients. ${ }^{(25,26)}$ The HADS is a self-administered questionnaire that scores seven items each for anxiety (HADS-A) and depression (HADS-D) between 0 and 3. For HADS-D, a total score of $>10$ was considered to represent "definite" depression, and a score of 8-10 indicates "probable" depression and a score of $<8$ indicates absent depression. ${ }^{(33)}$

Ethical considerations. This study proceeded according to the principles of the Declaration of Helsinki. The study protocol was approved by the Ethical Committee of both the University of Nagasaki and Nagasaki Memorial Hospital, and written informed consent to participate was obtained from all patients.

Statistical analysis. Data were expressed means \pm SD. Differences between groups were tested for statistical significance using Student's $t$ test, the chi-square test or Fisher's exact probability test. Correlations between two variables were determined by Spearman's rank correlation coefficient. A multivariate analysis was performed for variables that were found to be significant in univariate analyses using a logistic regression analysis. Correlations were examined using a linear regression analysis with coefficients of correlation. All data were analyzed using the IBM SPSS statistics software program ver. 21 (IBM Co., Armonk, NY) on a computer with a Windows operating system. A $p$ value of less than 0.05 was considered to indicate statistical significance.

\section{Results}

Overall characteristics of 89 patients with type 2 diabetes. Of the 90 patients, one patient was not available for a physiological assessment using the HADS because of being hesitating to answer one question. Therefore, the remaining 89 patients were enrolled in the present study. The clinical characteristics of these patients were shown in Table 2 . The 89 patients with type 2 diabetes comprised $55(61.8 \%)$ men and $34(38.2 \%)$ women with a mean ( \pm SD) age of $62.8 \pm 7.8$ years (range, $41-82$ years). There were no differences between men and women with respect to age $(62.2 \pm 8.3$ years and $63.7 \pm 6.8$ years, respectively). The mean \pm SD of BMI was $25.8 \pm 4.8 \mathrm{~kg} / \mathrm{m}^{2}$, and did not significantly differ between men and women $\left(25.2 \pm 4.3\right.$ and $26.8 \pm 5.5 \mathrm{~kg} / \mathrm{m}^{2}$, respectively). With respect to physical activity, the mean $\pm \mathrm{SD}$ of PAL was $1.69 \pm 0.56 ; 54(60.7 \%)$ were classified as having a 
Table 2. Clinical characteristics of 89 patients with type 2 diabetes

\begin{tabular}{|c|c|}
\hline Characteristics & \\
\hline \multicolumn{2}{|l|}{ Sociodemographic and lifestyle variables } \\
\hline Men/Women & $55 / 34$ \\
\hline Age (years) & $62.8 \pm 7.8$ \\
\hline Height (m) & $1.61 \pm 0.01$ \\
\hline Body weight (kg) & $67.1 \pm 14.5$ \\
\hline BMI $\left(\mathrm{kg} / \mathrm{m}^{2}\right)$ & $25.8 \pm 4.8$ \\
\hline PAL & $1.69 \pm 0.56$ \\
\hline Daily sleeping hours (h) & $7.3 \pm 1.5$ \\
\hline Body weight during past 6 months (unchanged/gain/loss) & $59 / 18 / 12$ \\
\hline Currently employed (yes/no) & $39 / 50$ \\
\hline Living with family members (yes/no) & $74 / 15$ \\
\hline Coffee consumed per day (cup) & $1.8 \pm 1.8$ \\
\hline Green tea consumed per day (cup) & $3.5 \pm 2.9$ \\
\hline Black tea consumption (rarely/habitual) & $81 / 8$ \\
\hline Alcohol consumption (never/occasionally/habitually) & $48 / 18 / 23$ \\
\hline Cigarette smoking habit (never/habitual/unknown) & $63 / 25 / 1$ \\
\hline Habitual supplements (yes/no/unknown) & $23 / 19 / 47$ \\
\hline \multicolumn{2}{|l|}{ Diabetic and other medical variables } \\
\hline Duration of diabetes ( $<5 / 5-10 / 10-15 />15 /$ unknown, years) & $29 / 20 / 16 / 23 / 1$ \\
\hline Hemoglobin A1c (\%) & $6.96 \pm 0.99$ \\
\hline Insulin treatment (yes/no) & $11 / 78$ \\
\hline Microvascular complications (present/absent) & $24 / 65$ \\
\hline Insomnia (yes/no) & $22 / 67$ \\
\hline Nutritional counseling sessions (yes/no) & $76 / 13$ \\
\hline Duration of nutritional counseling sessions (min) & $30.2 \pm 4.2$ \\
\hline Recommended daily total energy intake (kcal) & $1,592 \pm 168$ \\
\hline \multicolumn{2}{|l|}{ Nutrient intake per day estimated from FFQg questionnaire } \\
\hline Total energy (kcal) & $1,545 \pm 297$ \\
\hline Protein $(g)$ & $56.8 \pm 13.1$ \\
\hline Protein energy ratio $(\%)$ & $14.7 \pm 2.2$ \\
\hline Total lipids (g) & $47.7 \pm 14.4$ \\
\hline Lipid energy ratio (\%) & $27.7 \pm 6.2$ \\
\hline Carbohydrates $(\mathrm{g})$ & $205.9 \pm 47.7$ \\
\hline Carbohydrate energy ratio (\%) & $57.6 \pm 7.5$ \\
\hline
\end{tabular}

level; FFQg, food frequency questionnaire based on food groups; SD, standard deviation.

PAL level of I, $11(12.4 \%)$ were classified as having a PAL level of II, and $24(27.0 \%)$ were classified as having a PAL level of III. The mean \pm SD of amount of daily sleeping hours was $7.3 \pm 1.5 \mathrm{~h}$ per day. During the past 6 months, $18(20.2 \%)$ patients gained weight, and $12(13.5 \%)$ lost weight. Of the 89 patients, $50(56.2 \%)$ were not employed and $15(16.9 \%)$ lived alone. The mean daily cups (approximately $150 \mathrm{ml} / \mathrm{cup}$ ) of coffee consumption were $1.8 \pm 1.8$ cups (never drink in 30 patients, $1-1.5$ cups in 17 patients, 2 cups in 13 patients, 3 cups in 14 patients, 4 cups in 3 patients, 5 cups in 7 patients, 6 cups in 4 patients and unknown in 1 patient). There was no correlation between daily sleeping hours and coffee consumption $(r=-0.190, p=0.075)$. The mean daily cups of green tea consumption were $3.5 \pm 2.9$ cups (never drink in 16 patients, 1 cup in 3 patients, 2 cups in 19 patients, 3 cups in 17 patients, 4 cups in 5 patients, 5 cups in 12 patients, 6 cups in 3 patients, 7 cups in 2 patients, 8 cups in 3 patients, 10 cups in 7 patients, 11 cups in 1 patient and unknown in 1 patient). Eight $(9.0 \%)$ patients habitually consumed black tea (never drink in 80 patients, 1 cup in 4 patients, 2 cups in 4 patients and unknown in 1 patient). With respect to alcohol intake, 48 (53.9\%) were never drinker (19 men and 29 women), 18 (20.2\%) were occasional drinker ( 15 men and 3 women), and $23(25.8 \%)$ were habitual drinker ( 21 men and 2 women). Twenty-five (28.4\%) patients had smoking habits ( 20 men and 5 women); $1-50$ cigarettes per week in 7 patients, $51-100$ cigarettes per week in 13 patients, $101-150$ cigarettes per week in 4 patients, and 280 cigarettes per week in one patient. Supplements were reported to be habitually consumed for nutritional or health-related purposes in 23 patients; 11 consumed black or other kinds of vinegar, and 7 consumed green juice "aojiru".

The duration of diabetes was less than 5 years in 29 patients $(32.6 \%), 5-10$ years in $20(22.5 \%)$ patients, $10-15$ years in 16 $(18.0 \%)$ patients, more than 15 years in $23(25.8 \%)$ patients, and unknown in one patient. Thirty-four $(38.2 \%)$ patients had ever been hospitalized before up to 5 times. The mean \pm SD of $\mathrm{HbAlc}$ level was $6.96 \pm 0.99 \% ; \geq 8.0 \%$ in $12(13.5 \%)$ patients, $<8.0-7.0 \%$ in $22(24.7 \%)$ patients, $<7.0-6.0 \%$ in $50(56.2 \%)$ patients, and $<6.0 \%$ in $5(5.6 \%)$ patients. Treatments with insulin, dipeptidyl peptidase-4 (DPP-4) inhibitor, sulfonylurea, and $\alpha$-glucosidase inhibitors was administered to $11(12.4 \%), 52(58.4 \%), 51(57.3 \%)$, and $42(47.2 \%)$ patients, respectively. Diabetic microvascular complications were evident in $24(27.0 \%)$ patients with the most frequent being retinopathy (13 patients), followed by neuropathy (12 patients) and nephropathy (2 patients). Fifty-one $(57.3 \%)$ patients had hypertension, and $22(24.7 \%)$ suffered from insomnia. Of the 89 patients, $76(85.4 \%)$ had ever received nutritional education (counseling) at least once. Of the 76 patients, 26 had received nutritional counseling with his (her) spouse. The mean \pm SD of duration of one nutritional counseling session was $30.2 \pm 4.2 \mathrm{~min}$. The mean $\pm \mathrm{SD}$ of recommended daily total 


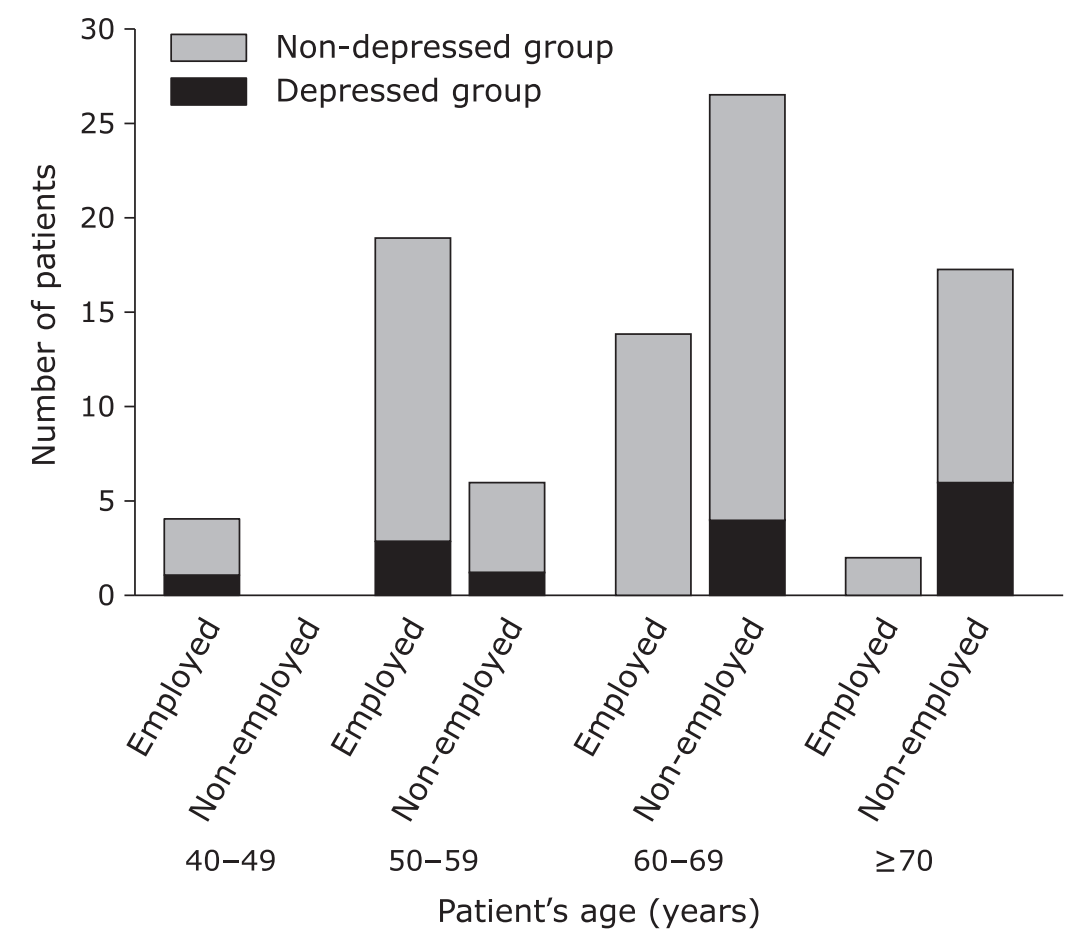

Fig. 1. Current employment status in depressed and non-depressed patients.

energy intake indicated by his (her) doctor was $1,592 \pm 168 \mathrm{kcal}$ $(n=62) ; 1,200-1,520 \mathrm{kcal}$ in 17 patients, $1,600-1,760 \mathrm{kcal}$ in 38 patients, and 1,800-2,000 kcal in 7 patients.

The mean \pm SD of intakes of total energy, protein, total lipids and carbohydrates per day were $1,545 \pm 297$ (kcal), $56.8 \pm 13.1$ (g), $47.7 \pm 14.4(\mathrm{~g})$ and $205.9 \pm 47.7(\mathrm{~g})$, respectively. The mean \pm SD of intakes of potassium, calcium, magnesium, iron, zinc, $\alpha$-carotene, $\beta$-carotene, vitamin $\mathrm{D}$, vitamin $\mathrm{K}$, vitamin $\mathrm{B} 6$, vitamin $\mathrm{B} 12$, folic acid, saturated fatty acids, monounsaturated fatty acids, PUFAs, cholesterol, total fibers, salt, $n-3$ PUFAs, and $n$-6 PUFAs were $1,960 \pm 592(\mathrm{mg}), 466 \pm 204(\mathrm{mg}), 193 \pm 54$ $(\mathrm{mg}), 5.9 \pm 1.8(\mathrm{mg}), 6.7 \pm 1.6(\mathrm{mg}), 515 \pm 290(\mu \mathrm{g}), 3,138 \pm$ $1,715(\mu \mathrm{g}), 7.2 \pm 3.3(\mu \mathrm{g}), 173 \pm 75(\mu \mathrm{g}), 1.0 \pm 0.3(\mathrm{mg}), 6.9 \pm 2.9$ $(\mu \mathrm{g}), 248 \pm 86(\mu \mathrm{g}), 14.6 \pm 5.0(\mathrm{~g}), 16.6 \pm 5.6(\mathrm{~g}), 9.3 \pm 3.1(\mathrm{~g})$, $299 \pm 117(\mathrm{mg}), 10.9 \pm 3.7(\mathrm{~g}), 7.5 \pm 2.6(\mathrm{~g}), 2.0 \pm 0.7(\mathrm{~g})$, and $7.3 \pm 2.6(\mathrm{~g})$, respectively. The mean $( \pm \mathrm{SD})$ protein energy ratio, lipid energy ratio, carbohydrate energy ratio, and $n-6 / n-3$ PUFAs were $14.7 \pm 2.2(\%), 27.7 \pm 6.2(\%), 57.6 \pm 7.5(\%)$, and $3.9 \pm 1.1$, respectively. Among these nutrients, the mean daily intakes of total energy, total fiber, and $n-3$ PUFAs were lower, and the mean lipid energy ratio was higher than the estimated average requirements, recommended dietary allowance and tentative dietary goals for preventing lifestyle-related diseases recommended in the 2010 version of the Dietary Reference Intakes for Japanese. ${ }^{(32)}$

Psychological assessment. Of the 90 patients, 89 were available for a physiological assessment using the HADS. Kugaya et $a{ }^{(34)}{ }^{(34)}$ reported that an optimal cut-off point for the screening of major depressive disorder was a total score of 10/11 for HADS-D which gave $82.4 \%$ sensitivity and 95.1 specificity. Therefore, 89 patients were divided into two groups, i.e., "definite" depressive state (a total score of $>10$, depressed group) and "probable" or "absent" depressive state (non-depressed group) in the present study. As a result, $15(16.9 \%)$ were classified as a depressed group and $74(83.1 \%)$ were classified as exhibiting a non-depressed group.
Comparison of characteristics between depressed and non-depressed groups. Male patients were more common in the depressed group than the non-depressed group $(p=0.040)$. There were no statistical differences in age, BMI, PAL, sleeping hours, change of body weight during the past 6 months, being employed, living with family members, daily consumptions of green tea and black tea, smoking habit and habitual consumption of supplements between the depressed and non-depressed group. With respect to the status of being employed, none of the patients aged 60 years or more who were currently employed $(n=16)$ were depressed, whereas 10 out of 44 patients $(22.7 \%)$ aged 60 years or more who were not currently employed had depressed symptoms (Fig. 1). However, reasons for being unemployed such as depression or complications of diabetes were not examined. The distributions of daily coffee and green tea consumption in depressed and non-depressed patients were shown in Fig. 2. When patients were divided into two groups, i.e., patients who never drink or drink less than 3 cups of coffee per day and patients who drink 3 or more cups of coffee per day, patients who drink 3 or more cups of coffee per day were more common in the non-depressed group $(27 / 74=$ $36.5 \%)$ than in the depressed group $(1 / 14=7.1 \%)(p=0.032)$. Duration of diabetes, HbAlc levels, medical treatment regimens including insulin, presence of diabetic microvascular complications (diabetic neuropathy, retinopathy, and nephropathy), presence of insomnia, number and duration ( $\mathrm{min}$ ) of nutritional counseling sessions were similar between the two groups (Table 3 ).

Among the nutrients listed in Table 1, daily intakes of total energy, water, protein, ash, potassium, calcium, magnesium, phosphate, iron, zinc, retinol, $\alpha$-carotene, $\beta$-carotene, cryptoxanthin, equivalent amount of $\beta$-carotene, equivalent amount of retinol, $\alpha$-tocopherol, $\beta$-tocopherol, $\gamma$-tocopherol, $\delta$-tocopherol, equivalent amount of tocopherol, vitamin $\mathrm{K}$, vitamin $\mathrm{B} 1$, vitamin $\mathrm{B} 2$, folic acid, pantothenic acid, vitamin $\mathrm{C}$, saturated fatty acids, monounsaturated fatty acids, PUFAs, cholesterol, water-soluble fibers, water-insoluble fibers, total fibers, total fatty acids, $n-3$ PUFAs, and $n-6 / n-3$ PUFAs tended to be lower among the 

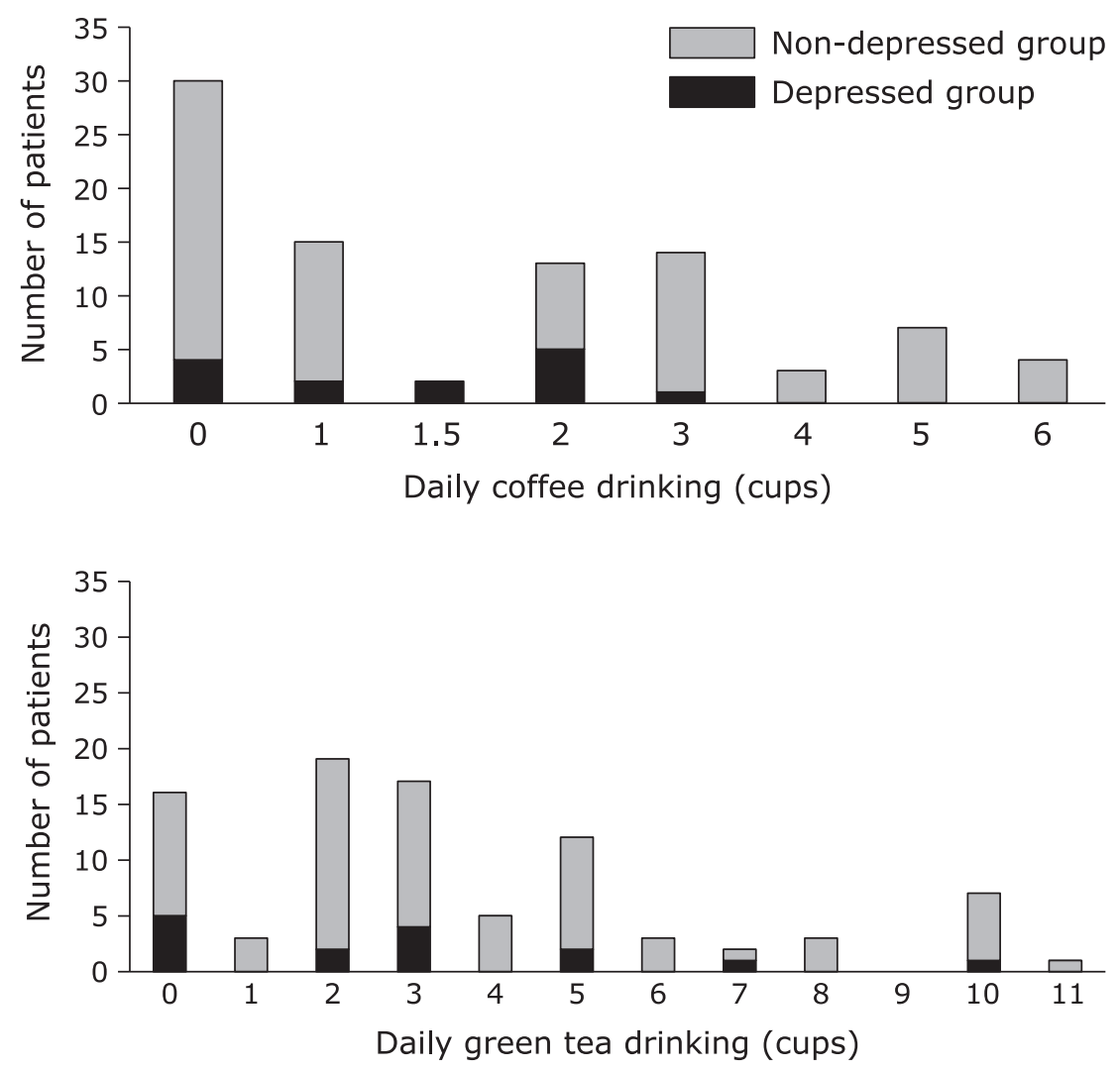

Fig. 2. Daily coffee and green tea consumption in depressed and non-depressed patients.

depressed group, but the difference did not reach statistical significance. Daily intakes of total lipids and $n-6$ PUFAs were significantly lower in depressed group than in non-depressed group. Lipid energy ratio was significantly lower, and carbohydrate energy ratio was significantly higher in depressed group than in non-depressed group (Table 4). Intake of foods among the food groups listed in Table 1 including alcohol consumption and dish categories was similar between the two groups (data not shown).

Independent predictors of depression determined according to logistic regression analysis. Logistic regression analysis selected only daily coffee consumption as an independent predictor of depression among the variables of sex, daily consumption of coffee, lipids and $n-6$ PUFAs, and the lipid and carbohydrate energy ratios that significantly differed between the depressed and non-depressed groups (Table 5).

\section{Discussion}

The reported prevalence of depression diagnosed from structured diagnostic interviews of diabetic patients ranges from 11.0 to $19.9 \%$ in uncontrolled studies. ${ }^{(5)}$ Our results evaluated by HADS were within this range because $16.9 \%$ had a "definite" depressive state. However, male patients were more prevalent in the depressed group than the non-depressed group, and the duration of diabetes, HbAlc levels, presence of diabetic microvascular complications, and PAL were similar between the two groups. These results were inconsistent with published studies showing that in general, twice as many women than men develop depression. ${ }^{(4,35)}$ Hyperglycemia might contribute to depression through its effects on symptoms such as fatigue and difficult concentrating and fear of complications, ${ }^{(6)}$ and mean HbAlc levels were significantly higher in depressed patients with type 2 diabetes. ${ }^{(8)}$
Diabetic complications, specifically neuropathy, was independently associated with depression in patients with diabetes, ${ }^{(5)}$ and having diabetic complications further negatively impacted on the quality of life. ${ }^{(8)}$ Physical activity protected older adults against depression. ${ }^{(36)}$ Patients with both depression and diabetes had a higher symptom burden due to increased functional impairment comprising poorer adherence to diet, exercise and medications and higher HbAlc levels, and they are at increased risk for the development of cardiovascular complications of diabetes, higher mortality rates and higher health care costs. ${ }^{(6,7)}$ These previously reported observations are not absolutely true in Japanese patients with diabetes because Yoshida et al. ${ }^{(5)}$ found no relationship between depression and the following factors; female gender, younger age, poor glycemic control, and duration of diabetes. Tsujii et al. ${ }^{(37)}$ also found no association between glycemic control and depressive symptoms in Japanese patients with type 2 diabetes.

Appetite changes are a common feature of depressive illness, and a poor-quality diet might be a result, rather than a cause of mental health issues. ${ }^{(23)}$ In the present study, the mean daily intake of total energy $(1,545 \mathrm{kcal})$ was lower than the estimated average requirements, recommended dietary allowance and tentative dietary goals for preventing lifestyle-related diseases recommended in the 2010 version of the Dietary Reference Intakes for Japanese. ${ }^{(32)}$ This may be influenced by the nutritional education program and/or the recommended daily total energy intake indicated by his (her) doctor (mean 1,592 kcal, $n=62$ ). In the present study, daily intakes of total lipids and $n-6$ PUFAs, and lipid energy ratio were significantly lower in depressed group than in nondepressed group. These results were not in line with recent studies showing that low dietary intake of $n-3$ PUFAs, ${ }^{(9,10)}$ and higher ratios of $n-6$ to $n-3$ PUFA ${ }^{(9)}$ are linked to depression. The reason for these discrepant results is obscure. Le Port et al. ${ }^{(20)}$ also 
Table 3. Comparison of main sociodemographic, lifestyle, and medical characteristics between depressed group and non-depressed groups

\begin{tabular}{|c|c|c|c|}
\hline Characteristics & $\begin{array}{l}\text { Depressed group } \\
\quad(n=15)\end{array}$ & $\begin{array}{l}\text { Non-depressed group } \\
\qquad(n=74)\end{array}$ & $p$ \\
\hline \multicolumn{4}{|l|}{ Sociodemographic and lifestyle variables } \\
\hline Age (years) & $63.3 \pm 9.2$ & $62.7 \pm 7.5$ & 0.800 \\
\hline Gender (men/women) & $13 / 2$ & $42 / 32$ & 0.040 \\
\hline BMI $\left(\mathrm{kg} / \mathrm{m}^{2}\right)$ & $23.7 \pm 4.6$ & $26.2 \pm 4.8$ & 0.065 \\
\hline PAL & $1.66 \pm 0.53$ & $1.69 \pm 0.57$ & 0.816 \\
\hline PAL (Level I/II/III) & $10 / 3 / 2$ & $44 / 8 / 22$ & 0.351 \\
\hline Daily sleeping hours (h) & $7.8 \pm 2.1$ & $7.1 \pm 1.4$ & 0.110 \\
\hline Body weight during past 6 months (unchanged/gain/loss) & $9 / 3 / 3$ & $50 / 15 / 9$ & 0.639 \\
\hline Currently employed (yes/no) & $4 / 11$ & $35 / 39$ & 0.165 \\
\hline Living with family members (yes/no) & $12 / 3$ & $62 / 12$ & 0.712 \\
\hline Coffee consumed per day (0-2/ $\geq 3$ cups) & $13 / 1$ & $47 / 27$ & 0.032 \\
\hline Green tea consumed per day (0-2/ $\geq 3$ cups) & $7 / 8$ & $31 / 42$ & 0.819 \\
\hline Black tea consumption (rarely/habitual) & $12 / 3$ & $69 / 5$ & 0.129 \\
\hline Alcohol consumption (never/occasionally/habitually) & $6 / 4 / 5$ & $42 / 14 / 18$ & 0.480 \\
\hline Cigarette smoking habit (never/habitual) & $9 / 5$ & $54 / 20$ & 0.528 \\
\hline Habitual supplements (yes/no) & $3 / 5$ & $20 / 14$ & 0.433 \\
\hline \multicolumn{4}{|l|}{ Diabetic and other medical variables } \\
\hline Duration of diabetes (years) $(<5 / 5-10 / 10-15 />15)$ & $8 / 1 / 2 / 4$ & $21 / 19 / 14 / 19$ & 0.224 \\
\hline Hemoglobin A1c (\%) & $7.46 \pm 0.85$ & $7.02 \pm 1.10$ & 0.148 \\
\hline Insulin treatment (yes/no) & $3 / 12$ & $8 / 66$ & 0.387 \\
\hline Microvascular complications (present/absent) & $6 / 9$ & $18 / 56$ & 0.212 \\
\hline Insomnia (yes/no) & $4 / 11$ & $18 / 56$ & 1.000 \\
\hline Number of nutritional counseling sessions (times) & $2.4 \pm 1.8$ & $2.9 \pm 3.2$ & 0.622 \\
\hline Duration of nutritional counseling sessions (min) & $34.2 \pm 6.6$ & $30.0 \pm 2.4$ & 0.187 \\
\hline
\end{tabular}

Data are expressed as means \pm SD, or number of patients. BMI, body mass index; PAL, physical activity level; SD, standard deviation.

reported that low-fat dietary pattern was significantly associated with depressive symptoms in a prospective longitudinal study over a period of 10 years. Our results further showed that carbohydrate energy ratio was significantly higher in depressed group than in non-depressed group. A cross-sectional study by Westover et al. ${ }^{(38)}$ found a correlation between sugar consumption and annual rates of major depression. Sucrose taste stimulation increases levels of $\beta$-endorphins that can contribute to depression. Moreover, persistent hyperglycemia has been reported to be associated with increased generation of reactive oxygen species that can be linked to major depression. ${ }^{(38)}$ In the present study, total energy intake and protein energy ratio were similar in depressed and non-depressed groups. Therefore, lipid energy ratio resulted to be lower in depressed group because carbohydrate energy ratio was significantly higher in depressed group. It is possible that these food intake frequencies were influenced by the nutritional education program, but the depressed and non-depressed patients received the same amount of counseling in the present study.

In our present study, there was an inverse relationship between coffee, but not black or green tea consumption and depressive symptoms. Coffee, black and green tea are the primary dietary sources of caffeine among adults. ${ }^{(35)}$ Pham et al. ${ }^{\left({ }^{(9)}\right.}$ reported that green tea, coffee, and caffeine consumption was associated with a lower prevalence of depressive symptoms in their cross-sectional study. Chronic caffeine consumption has several biological effects. At low to moderate doses, caffeine has psychostimulant effects. Caffeine affects brain function mainly by its antagonist action against adenosine $\mathrm{A} 2 \mathrm{a}$ receptors and it functions in the modulation of dopaminergic neurotransmission. ${ }^{(35)}$ However, Ruusunen et al. ${ }^{(40)}$ reported that coffee consumption was associated with a lower risk of severe depression, whereas tea or caffeine consumption was not associated with the risk of depression in their prospective study of middle-aged Finnish men. They postulated that coffee acted as an independent protective factor against depression and that this effect was due to biologically active compounds other than caffeine. ${ }^{(40)}$ In addition to caffeine, coffee contains many functional components such as chlorogenic acid, ferulic acid, nicotinic acid, trigonelline, quinolinic acid, tannic acid, and pyrogallic acid. These compounds have anti-inflammatory or anti-oxidative effect that can be associated with the prevention or treatment of depression. Lucas et al. ${ }^{(35)}$ also reported that the risk of depression dose-dependently decreased with increasing consumption of caffeinated coffee in their prospective study of U.S. women. Their study also found that decaffeinated coffee or caffeine from non-coffee sources was not significantly associated with depression risk. ${ }^{(35)}$

Kawachi et al. ${ }^{(41)}$ described a close inverse association between coffee intake and risk of suicide. However, Tanskanen et al. ${ }^{(42)}$ reported that the association between daily coffee consumption and risk of suicide was $\mathrm{J}$-shaped, because the risk of suicide was $58 \%$ higher among individuals who consumed $\geq 8$ cups of coffee per day than among those who consumed more moderate amounts. These discrepant results might be associated with the proportions of individuals in each study who consumed large quantities of coffee. Excessive coffee/caffeine consumption can induce nervousness, fear, tension, palpitation, restlessness, and lead to anxiety or panic attacks in sensitive persons. ${ }^{(42)}$ In the present study, none of the patients consumed more than 8 cups of coffee per day. Therefore, daily coffee consumption was found to be an independent predictor of depression, although betweenperson variations in the strength of coffee brew, timing of coffee consumption and caffeinated/decaffeinated coffee distinction were not considered. Depression can also be correlated with sleeping hours, which might be affected by coffee consumption. However, there was no correlation between daily sleeping hours and coffee consumption and also, there was no statistical difference in daily sleeping hours or the prevalence of insomnia between the depressed and non-depressed group in the present study.

Several limitations of the present study must be considered. First, dietary data were obtained from a self-administered semi- 
Table 4. Comparison of main nutrient intake per day between depressed group and non-depressed group

\begin{tabular}{|c|c|c|c|}
\hline Nutrients* & $\begin{array}{l}\text { Depressed group } \\
\qquad(n=15)\end{array}$ & $\begin{array}{l}\text { Non-depressed group } \\
\qquad(n=74)\end{array}$ & $p$ \\
\hline Total energy (kcal) & $1,503 \pm 308$ & $1,553 \pm 296$ & 0.557 \\
\hline Protein $(g)$ & $55.3 \pm 17.1$ & $57.1 \pm 12.3$ & 0.640 \\
\hline Protein energy ratio (\%) & $14.5 \pm 2.5$ & $14.8 \pm 2.2$ & 0.621 \\
\hline Total lipids (g) & $41.0 \pm 13.8$ & $49.0 \pm 14.2$ & 0.050 \\
\hline Lipid energy ratio (\%) & $24.1 \pm 6.4$ & $28.4 \pm 6.0$ & 0.016 \\
\hline Carbohydrates (g) & $206.3 \pm 48.2$ & $205.8 \pm 47.9$ & 0.976 \\
\hline Carbohydrate energy ratio (\%) & $61.4 \pm 8.5$ & $56.8 \pm 7.1$ & 0.031 \\
\hline Potassium (mg) & $1,866 \pm 705$ & $1,980 \pm 570$ & 0.501 \\
\hline Calcium (mg) & $408 \pm 192$ & $478 \pm 205$ & 0.232 \\
\hline Magnesium (mg) & $188 \pm 61$ & $194 \pm 52$ & 0.709 \\
\hline Iron (mg) & $5.3 \pm 1.6$ & $6.0 \pm 1.8$ & 0.177 \\
\hline Zinc (mg) & $6.6 \pm 1.9$ & $6.8 \pm 1.5$ & 0.759 \\
\hline$\alpha$-carotene $(\mu \mathrm{g})$ & $470 \pm 214$ & $524 \pm 304$ & 0.515 \\
\hline$\beta$-carotene $(\mu \mathrm{g})$ & $2,860 \pm 1,304$ & $3,194 \pm 1,789$ & 0.495 \\
\hline Vitamin $D(\mu g)$ & $7.9 \pm 4.2$ & $7.1 \pm 3.1$ & 0.508 \\
\hline Vitamin $\mathrm{K}(\mu \mathrm{g})$ & $152 \pm 58$ & $178 \pm 77$ & 0.230 \\
\hline Vitamin B6 (mg) & $1.0 \pm 0.3$ & $1.0 \pm 0.3$ & 0.883 \\
\hline Vitamin B12( $\mu \mathrm{g})$ & $7.4 \pm 3.5$ & $6.8 \pm 2.7$ & 0.451 \\
\hline Folic acid $(\mu \mathrm{g})$ & $229 \pm 86$ & $252 \pm 86$ & 0.346 \\
\hline Saturated fatty acids (g) & $13.0 \pm 5.2$ & $14.9 \pm 4.9$ & 0.167 \\
\hline Monounsaturated fatty acids (g) & $14.3 \pm 5.0$ & $17.1 \pm 5.6$ & 0.079 \\
\hline Polyunsaturated fatty acids (g) & $8.0 \pm 2.4$ & $9.6 \pm 3.1$ & 0.064 \\
\hline Cholesterol (mg) & $282 \pm 119$ & $303 \pm 117$ & 0.525 \\
\hline Total fibers $(g)$ & $9.9 \pm 4.0$ & $11.1 \pm 3.7$ & 0.242 \\
\hline Salt (g) & $7.5 \pm 3.1$ & $7.5 \pm 2.5$ & 0.984 \\
\hline$n-3$ PUFAs (g) & $1.8 \pm 0.7$ & $2.0 \pm 0.7$ & 0.405 \\
\hline$n-6$ PUFAs (g) & $6.1 \pm 1.9$ & $7.5 \pm 2.6$ & 0.047 \\
\hline$n-6 / n-3$ PUFAs & $3.5 \pm 0.9$ & $3.9 \pm 1.2$ & 0.147 \\
\hline
\end{tabular}

Data are expressed as means \pm SD, or number of patients. *According to the 2010 edition of Standard Tables of Food Composition in Japan ${ }^{(29)}$. PUFAs, polyunsaturated fatty acids; SD, standard deviation.

Table 5. Independent predictors of depression determined by logistic regression analysis

\begin{tabular}{lcccc}
\hline Variables & $\begin{array}{c}\text { Regression } \\
\text { coefficient }\end{array}$ & Standard error & $p$ & $\begin{array}{c}\text { Adjusted } \\
\text { odds ratio }\end{array}$ \\
\hline Coffee consumed per day (0-2/ $\geq 3$ cups) & -2.506 & 1.105 & 0.023 & 0.082 \\
\hline
\end{tabular}

$\mathrm{Cl}$, confidence interval.

quantitative food questionnaire, which only covered specific foods and it is recognized as being less precise than dietary assessment using a diary questionnaire. ${ }^{(1,19)}$ Second, neither a structured psychiatric interview nor physician-diagnosed depression were adopted in the present study, although HADS has been shown to be reliable and valid for the screening of depression among Japanese patients. ${ }^{(25,26)}$ Third, causality could not be determined because this analysis is based on the cross-sectional study design. ${ }^{(5)}$ Moreover, because depressive symptoms were assessed only once, whether or not the depressive symptoms changed over time was not addressed. Therefore, whether the relationship between coffee consumption and depressive symptoms tracks over time remains unclear. ${ }^{(20)}$ Fourth, our study proceeded at a single institution with a small sample size; however, the participation rate was high $(86.5 \%)$. Finally, our results could be spurious if depressed patients tend to avoid coffee, or if health professionals

\section{References}

1 Miyaki K, Song Y, Htun NC, et al. Folate intake and depressive symptoms in Japanese workers considering SES and job stress factors: J-HOPE study. BMC Psychiatry 2012; 12: 33

2 Mezuk B, Eaton WW, Albrecht S, Golden SH. Depression and type 2 diabetes over the lifespan: a meta-analysis. Diabetes Care 2008; 31: 2383-2390. advise depressed patients not to consume coffee/caffeine. ${ }^{(41)}$

The depressed and non-depressed patients received the same amount of nutritional counseling in the present study. Physicians, nurses and dietitians need to pay more attention to diabetic metabolic changes among depressed patients for prevention and earlier detection of type 2 diabetes, ${ }^{(3)}$ and also, to the positive effect on quality of life in patients with type 2 diabetes by the early detection and treatment of depression. ${ }^{(8)}$ A prospective study is needed to determine whether coffee consumption contributes to the prevention or treatment of depressive symptoms in patients with type 2 diabetes.

\section{Conflict of Interest}

The authors declare no conflicts of interest (COI) in preparing this article.

3 Kawakami N, Takatsuka N, Shimizu H, Ishibashi H. Depressive symptoms and occurrence of type 2 diabetes among Japanese men. Diabetes Care 1999; 22: $1071-1076$

4 Anderson RJ, Freedland KE, Clouse RE, Lustman PJ. The prevalence of comorbid depression in adults with diabetes: a meta-analysis. Diabetes Care 
2001; 24: 1069-1078.

5 Yoshida S, Hirai M, Suzuki S, Awata S, Oka Y. Neuropathy is associated with depression independently of health-related quality of life in Japanese patients with diabetes. Psychiatry Clin Neurosci 2009; 63: 65-72.

6 Nouwen A, Nefs G, Caramlau I, et al. Prevalence of depression in individuals with impaired glucose metabolism or undiagnosed diabetes: a systematic review and meta-analysis of the European Depression in Diabetes (EDID) Research Consortium. Diabetes Care 2011; 34: 752-762.

7 Katon WJ, Von Korff M, Lin EH, et al. The pathways study: a randomized trial of collaborative care in patients with diabetes and depression. Arch Gen Psychiatry 2004; 61: 1042-1049.

8 Das R, Singh O, Thakurta RG, et al. Prevalence of depression in patients with type II diabetes mellitus and its impact on quality of life. Indian $J$ Psychol Med 2013; 35: 284-289.

9 Tiemeier H, van Tuijl HR, Hofman A, Kiliaan AJ, Breteler MM. Plasma fatty acid composition and depression are associated in the elderly: the Rotterdam Study. Am J Clin Nutr 2003; 78: 40-46.

10 Suzuki S, Akechi T, Kobayashi M, et al. Daily omega-3 fatty acid intake and depression in Japanese patients with newly diagnosed lung cancer. $\mathrm{Br} J$ Cancer 2004; 90: 787-793.

11 Hamazaki T, Sawazaki S, Itomura M, et al. The effect of docosahexaenoic acid on aggression in young adults. A placebo-controlled double blind study. J Clin Invest 1996; 97: 1129-1133.

12 Sublette ME, Ellis SP, Geant AL, Mann JJ. Meta-analysis of the effects of eicosapentaenoic acid (EPA) in clinical trials in depression. J Clin Psychiatry 2011; 72: 1577-1584.

13 Gilbody S, Lightfoot T, Sheldon T. Is low folate a risk factor for depression? A meta-analysis and exploration of heterogeneity. J Epidemiol Community Health 2007; 61: 631-637.

14 Nanri A, Mizoue T, Matsushita Y, et al. Serum folate and homocysteine and depressive symptoms among Japanese men and women. Eur J Clin Nutr 2010; 64: 289-296.

15 Tanskanen A, Hibbeln JR, Tuomilehto J, et al. Fish consumption and depressive symptoms in the general population in Finland. Psychiatr Serv 2001; 52. 529-531.

16 Sánchez-Villegas A, Delgado-Rodríguez M, Alonso A, et al. Association of the Mediterranean dietary pattern with the incidence of depression. Arch Gen Psychiatry 2009; 66: 1090-1098.

17 Hodge A, Almeida OP, English DR, Giles GG, Flicker L. Patterns of dietary intake and psychological distress in older Australians: benefits not just from a Mediterranean diet. Int Psychogeriatr 2013; 25: 456-466.

18 Nanri A, Kimura Y, Matsushita Y, et al. Dietary patterns and depressive symptoms among Japanese men and women. Eur J Clin Nutr 2010; 64: 832839.

19 Akbaraly TN, Brunner EJ, Ferrie JE, Marmot MG, Kivimaki M, SinghManoux A. Dietary pattern and depressive symptoms in middle age. $\mathrm{Br} \mathrm{J}$ Psychiatry 2009; 195: 408-413.

20 Le Port A, Gueguen A, Kesse-Guyot E, et al. Association between dietary patterns and depressive symptoms over time: A 10-year follow-up study of the GAZEL cohort. PLoS One 2012; 7: e51593.

21 Parker G, Gibson NA, Brotchie H, Heruc G, Rees AM, Hadzi-Pavlovic D. Omega-3 fatty acids and mood disorders. Am J Psychiatry 2006; 163: 969-978.

22 Murakami K, Mizoue T, Sasaki S, et al. Dietary intake of folate, other B vitamins, and omega-3 polyunsaturated fatty acids in relation to depressive symptoms in Japanese adults. Nutrition 2008; 24: 140-147.

23 Jacka FN, Pasco JA, Mykletun A, et al. Association of Western and traditional diets with depression and anxiety in women. Am J Psychiatry 2010; 167: 305-311.

24 Bloch MH, Hannestad J. Omega-3 fatty acids for the treatment of depression: systematic review and meta-analysis. Mol Psychiatry 2012; 17: 1272-1282.

25 Higashi A, Yashiro H, Kiyota K, et al. [Validation of the hospital anxiety and depression scale in a gastro-intestinal clinic]. Nihon Shokakibyo Gakkai Zasshi 1996; 93: 884-892 (in Japanese, Abstract in English).

26 Okami Y, Kato T, Nin G, et al. Lifestyle and psychological factors related to irritable bowel syndrome in nursing and medical school students. $J$ Gastroenterol 2011; 46: 1403-1410.

27 Seino Y, Nanjo K, Tajima N, et al; The Committee of the Japan Diabetes Society on the diagnostic criteria of diabetes mellitus. Report of the Committee on the classification and diagnostic criteria of diabetes mellitus. Diabetol Int 2010; 1: 2-20.

28 Takahashi K, Yoshimura Y, Kaimoto T, Kunii D, Komatsu T, Yamamoto S. [Validation of a food frequency questionnaire based on food groups for estimating individual nutrient intake]. Eiyogaku Zasshi 2001; 59: 221-232 (in Japanese, Abstract in English).

29 Council for Science and Technology, Ministry of Education, Culture, Sports, Science and Technology, Japan. Standard Tables of Food Composition in Japan 2010. Tokyo: Kagawa Education Institute of Nutrition, 2010; (in Japanese).

30 Yoshiike N, Hayashi F, Takemi Y, Mizoguchi K, Seino F. A new food guide in Japan: the Japanese food guide spinning top. Nutr Rev 2007; 65: 149-154.

31 Ishikawa-Takata K, Tabata I, Sasaki S, et al. Physical activity level in healthy free-living Japanese estimated by doubly labelled water method and International Physical Activity Questionnaire. Eur J Clin Nutr 2008; 62: 885891.

32 Department of Nutritional Epidemiology, National Institute of Health and Nutrition, Japan 2011-2012. Dietary Reference Intakes for Japanese -2010The summary report from the Scientific Committee of "Dietary Reference Intakes for Japanese". (http://www0.nih.go.jp/eiken/english/research/pdf/ dris2010_eng.pdf).

33 Zigmond AS, Snaith RP. The hospital anxiety and depression scale. Acta Psychiatr Scand 1983; 67: 361-370.

34 Kugaya A, Akechi T, Okuyama T, Okamura H, Uchitomi Y. Screening for psychological distress in Japanese cancer patients. Jpn J Clin Oncol 1998; 28: 333-338.

35 Lucas M, Mirzaei F, Pan A, et al. Coffee, caffeine, and risk of depression among women. Arch Intern Med 2011; 171: 1571-1578.

36 Strawbridge WJ, Deleger S, Roberts RE, Kaplan GA. Physical activity reduces the risk of subsequent depression for older adults. Am J Epidemiol 2002; 156: 328-334

37 Tsujii S, Hayashino Y, Ishii H; Diabetes Distress and Care Registry at Tenri Study Group. Diabetes distress, but not depressive symptoms, is associated with glycaemic control among Japanese patients with type 2 diabetes: Diabetes Distress and Care Registry at Tenri (DDCRT 1). Diabet Med 2012; 29: $1451-1455$.

38 Westover AN, Marangell LB. A cross-national relationship between sugar consumption and major depression? Depress Anxiety 2002; 16: 118-120.

39 Pham NM, Nanri A, Kurotani K, et al. Green tea and coffee consumption is inversely associated with depressive symptoms in a Japanese working population. Public Health Nutr 2014; 17: 625-633.

40 Ruusunen A, Lehto SM, Tolmunen T, Mursu J, Kaplan GA, Voutilainen S. Coffee, tea and caffeine intake and the risk of severe depression in middle-aged Finnish men: the Kuopio Ischaemic Heart Disease Risk Factor Study. Public Health Nutr 2010; 13: 1215-1220.

41 Kawachi I, Willett WC, Colditz GA, Stampfer MJ, Speizer FE. A prospective study of coffee drinking and suicide in women. Arch Intern Med 1996; 156: $521-525$.

42 Tanskanen A, Tuomilehto J, Viinamaki H, Vartiainen E, Lehtonen J, Puska P. Heavy coffee drinking and the risk of suicide. Eur J Epidemiol 2000; 16: 789-791. 